\title{
New Method of Manganese-Enhanced Magnetic Resonance Imaging (MEMRI) for Rat Brain Research
}

\author{
Keun-Yeong JEONG ${ }^{1,2)}$, Chulhyun $\mathrm{LEE}^{3)}$, Jee-Hyun $\mathrm{CHO}^{3)}$, Ji-Hyuk $\mathrm{KANG}^{1,4)}$ and Heung-Sik NA ${ }^{2)}$ \\ 1) Neuroscience Research Institute and Department of Biotechnology and Science, Korea University College of \\ Medicine, 126-1 Anam-dong, 5 Ga, Seongbuk-Gu, Seoul 136-705, Republic of Korea \\ ${ }^{2)}$ Neuroscience Research Institute and Department of Physiology, Korea University College of Medicine, 126-1 \\ Anam-dong, 5 Ga, Seongbuk-Gu, Seoul 136-705, Republic of Korea \\ ${ }^{3)}$ Division of Magnetic Resonance Research, Korea Basic Science Institute, 804-1 Yangcheong-Ri, Ochang, \\ Cheongwon, Chungbuk 363-883, Republic of Korea \\ 4) Department of Biomedical Laboratory Science, College of Health and Welfare, Kyungwoon University, 730 \\ Kangdong-ro, Sandong-myeon, Gumi, Gyeongbuk, 730-739, Republic of Korea
}

\begin{abstract}
Manganese $\left(\mathrm{Mn}^{2+}\right)$-enhanced MRI (MEMRI) is known to provide insight into functional and anatomical biology. However, this method, which uses $\mathrm{Mn}^{2+}$ as a MRI-detectable contrast agent, has drawbacks such as the toxicity to cells beyond a certain level of $\mathrm{Mn}^{2+}$. In this study, we attempt to determine a new method of ICV administration, the optimal concentration of administered $\mathrm{Mn}^{2+}$ and the optimal MEMRI acquisition time following administration. Male Sprague-Dawley rats were used in the following experimental sessions: (1) intracerebroventricular (ICV) cannula implantation in the region of the cisterna magna, (2) serial dilution of $\mathrm{MnCl}_{2}(20-80 \mathrm{mM})$, (3) ICV administration of $\mathrm{MnCl}_{2}$ through the cannula, and (4) $\mathrm{T}_{1}$-weighted MRI measurements. We confirmed that cannula implantation in the region of the cisterna magna was a new ICV injection method for the administration of a contrast agent. The optimal concentration for MEMRI was $20 / 50 \mathrm{mM} / \mu \mathrm{l}$ of $\mathrm{MnCl}_{2}$. The MEMRI data acquired at different time points indicate that most signal enhancement is maintained during $14-48 \mathrm{~h}$ after contrast agent injection, and $24 \mathrm{~h}$ was the optimal time to acquire images of the rat brain. The present study offers optimized parameters for contrast agent injection that would be a good basis for studies using MEMRI to research the rat brain.
\end{abstract}

Key words: cannula implantation, intracerebroventricular injection, manganese-enhanced $\mathrm{MRI}, \mathrm{Mn}^{2+}$, rat brain

\section{Introduction}

In the past decade, Magnetic Resonance Imaging (MRI) has been one of the most important noninvasive imaging modalities in clinical diagnostics and research $[1,2]$ (Table 1). Recently, a manganese-based functional MRI technique known as manganese-enhanced MRI (MEMRI) was described as being independent of hemodynamic changes [3]. $\mathrm{Mn}^{2+}$ is used both as a con- trast agent and a tracer that allows for noninvasive visualization of the brain neuroarchitecture $[4,6]$ and functionally active regions in the CNS $[5,7]$. It is also a paramagnetic ion that causes shortening of the $\mathrm{T}_{1}$ relaxation time of water protons in MRI, which leads to a strong contrast enhancement in $\mathrm{T}_{1}$-weighted MRI [8]. Hence, $\mathrm{Mn}^{2+}$ has been very useful for visualizing the brain architecture. Recent studies have demonstrated the usefulness of $\mathrm{Mn}^{2+}$ in providing cytoarchitectonic con- 
Table 1. Increase in citation index of MEMRI and $\mathrm{Mn}^{+}$(2000-2010)

\begin{tabular}{lccccccccccc}
\hline Year & 2000 & 2001 & 2002 & 2003 & 2004 & 2005 & 2006 & 2007 & 2008 & 2009 & 2010 \\
\hline Citation index & 627 & 828 & 1106 & 1480 & 1680 & 1890 & 2090 & 2290 & 2580 & 2600 & 2700 \\
\hline
\end{tabular}

trast to the rodent brain [9-14].

$\mathrm{Mn}^{2+}$ is an essential heavy metal that is a cofactor in a number of important enzymes such as manganese superoxide dismutase, pyruvate carboxylase, and glutamine synthetase $[15,16]$. However, a major problem beyond a certain level of $\mathrm{Mn}^{2+}$ is its cellular toxicity, in particular its well-known ability to cause movement disorders such as Parkinson's disease [17-19]. Concomitant to improvements in the sensitivity of MEMRI techniques, it is equally important to use lower concentrations of $\mathrm{Mn}^{2+}$ and develop new ways to administer the contrast agent directly into the target organ.

Arising from this perspective, many studies have explored the route of $\mathrm{Mn}^{2+}$ injection, toxicity of the injection dose, sensitivity to anatomical structure analysis, changes in signal intensity according to the time-course after injection, the development of new types of injected contrast, and the development of new types of contrast agent [20-22]. Many studies reported that the negative side effects and fatality rate are increased beyond a certain level of $\mathrm{Mn}^{2+}$. For this reason, the microstructure can be observed following administration of a certain dose $[9,19,23,24]$, and the optimal observation time is dependent upon the injection route and applied model [26]. However, MEMRI studies of various animal models are needed in addition to the current literature to better analyze the different injection routes of manganese and the optimal doses and observation periods. Thus, although a study on injecting $\mathrm{MnCl}_{2}$ through the cisterna magna has been conducted, more detailed research for stable and accurate administration of $\mathrm{MnCl}_{2}$ into the cerebrospinal fluid (CSF) must be performed [25].

In the present study, we carried out experiments to find a new ICV injection method for $\mathrm{MnCl}_{2}$ administration for stable acquisition of anatomical images of the rat brain by MEMRI and observed the physiological reaction of rats according to the doses of $\mathrm{MnCl}_{2}$ (Table 1).

\section{Materials and Methods}

The experimental procedure in this study consisted of four steps: (1) serial dilution of the contrast agent
$\left(\mathrm{MnCl}_{2}\right)$, (2) intracerebroventricular (ICV) cannula implantation, (3) ICV cannula administration of $\mathrm{MnCl}_{2}$, and (4) $\mathrm{T}_{1}$-weighted MRI measurements.

\section{Animal preparation}

All experiments were carried out in accordance with animal care guidelines described in Korean law (828213, revised 2007. 1. 26) and the guidelines set by the Korea University College of Medicine Animal Research Policies Committee. Sprague-Dawley (SD) rats were obtained from Samtako Co. (Osan, Korea) and bred under specific-pathogen-free (SPF) conditions. Pregnant SD-rats were acquired 1 week before parturition and individually housed in plastic cages with sawdust bedding. The newborn rats were weaned at the age of 3 weeks; at that time, male and female rats were separated. The cannula implantation was conducted when the rats were 4 weeks of age, and image acquisition and analyses were performed when they were 5 weeks of age. In total, 35 male rats were used in the present study. All animals were raised in a room that maintained a $12-\mathrm{h} / 12-\mathrm{h}$ light/ dark cycle (lights on at 07:00) and a temperature of $22-25^{\circ} \mathrm{C}$, with free access to food and water.

\section{Serial dilution of the contrast agent}

$\mathrm{MnCl}_{2}-4 \mathrm{H}_{2} \mathrm{O}$ (Sigma-Aldrich, St. Louis, MO, USA) was used as the contrast agent to obtain images of the rat brain. The contrast agent was dissolved in isotonic pH-buffered physiological saline at agent concentrations of $80,60,40,30$, and $20 \mathrm{mM}$. All mixtures were kept at approximately $4^{\circ} \mathrm{C}$.

\section{Cannula implantation}

The animals were placed in a small acrylic cage that was coupled with an anesthesia machine that allowed them to breathe freely under gaseous anesthesia (2\% isoflurane, Spartanburg, SC, USA). After full anesthesia of an animal was achieved, it was positioned on an operating table (while maintaining the gaseous anesthesia) with the superior aspect of the neck hyperextended to expose the posterior region.

The animal fur was shaved with an electric clipper 

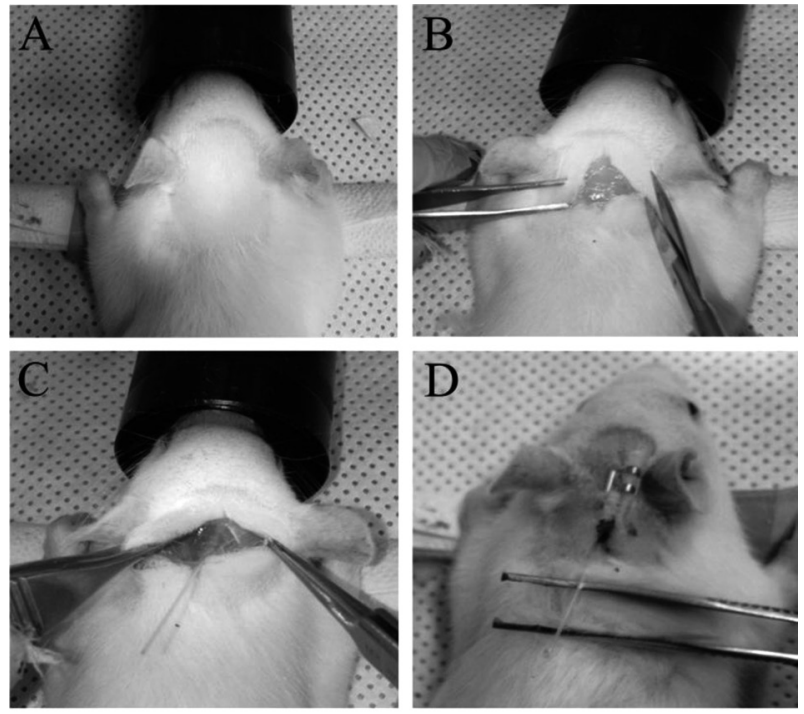

$\mathrm{E}$

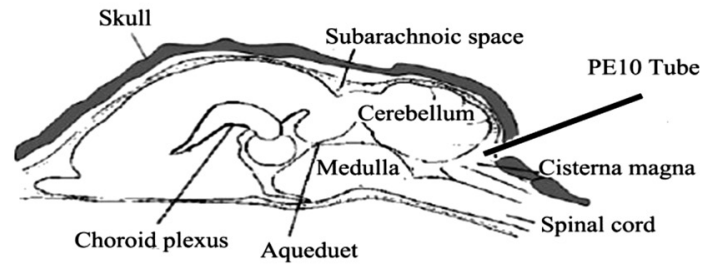

Fig. 1. The procedure for cannula implantation. (A) Before surgery. (B) The atlanto-occipital membrane was secured through an incision in the triple layer muscles. (C) After the atlanto-occipital membrane was punctured, an intrathecal (IT) catheter (PE-10 tube) was inserted. (D) The cannula was fixed, and the incised part was restored. E. Schematic diagram of cannula-implantation.

from the posterior region of the neck to the occiput, and the skin was swabbed with iodine. The midline of the posterior region of the neck skin was vertically sectioned into $1-\mathrm{cm}$ parts, and the muscles were exposed. An incision was made directly into the midline of the triple layers of muscle, and the muscles were spread with surgical scissors. After these steps, the foramen magnum was visible between the muscles. The vicinity of foramen magnum was cleaned with sterile gauze and cotton tips. Next, a 30-mm PE10 polyethylene tube (BD, Franklin Lakes, NJ, USA) was carefully inserted into the cerebral ventricle (forth ventricle) through the foramen magnum. All polyethylene tubes were precut to each size and filled with physiological saline. A 27.5-gauge needle and 5-mm PE20 polyethylene tube (BD) were used as an entrance cover for the PE10 tube. After surgery, each animal was returned to its cage. The animals were checked every 3 $\mathrm{h}$ during recovery (Fig. 1).
A.
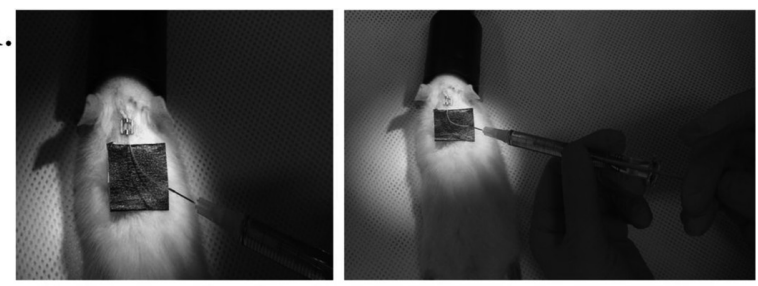

B.
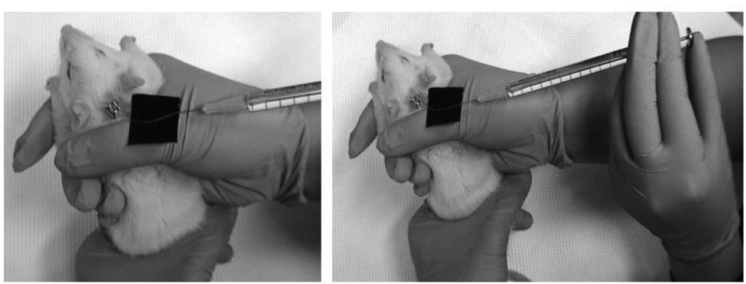

Fig. 2. Administration of contrast agent. The contrast agent could be administered both of under anesthesia (A) and during the waking state (B).

\section{ICV administration of the contrast agent}

Seven days after the surgery, contrast agent was administered into the rats after inspection to confirm the cannula placement and wound healing. A various range of concentrations of $\mathrm{MnCl}_{2}(20-80 \mathrm{mM}$, as described above) in a volume of $50 \mu 1$ was injected by a Hamilton syringe (100 $\mu$, Hamilton Co., Reno, NV, USA). The contrast agent was manually injected into the cisterna magna via the implanted cannula using a 27 -gauge needle under anesthesia or during the waking state (Fig. 2). After administration, the rats were observed to determine whether or not the contrast agent had adverse effects (Fig. 2).

\section{MEMRI sequence}

The acquisition of anatomical images of the rat brain was performed following ICV administration of the contrast agent. For this, MEMRI was carried out at a range of time points (1-96 h) after administration. Isoflurane was used to maintain the anesthetization (induction 4\%, maintenance $2 \%$ ) for MEMRI, and a flow of warm water through a pipe underneath the animal cradle was used to prevent hypothermia due to anesthesia. A respiration sensor was attached to the body, and the stability of breathing was observed via physiological monitoring system.

MRI experiments were performed on a 4.7 T MRI system (Bruker, BioSpec 47/40, Etlingen, Germany) at the Korea Basic Science Institute (Cheong-won, Chungbuk, South Korea). A rat brain surface coil was used as 
Table 2. Assessment of animal behavior following $\mathrm{MNCL}_{2} \mathrm{ICV}$ administration based on the concentration difference

\begin{tabular}{cll}
\hline Concentration in $50 \mu \mathrm{l}$ & $\mathrm{n}$ & \multicolumn{1}{c}{ Remarks } \\
\hline $80 \mathrm{mM}$ & 2 & $\begin{array}{l}\text { - Respiratory rate unstable under anesthesia } \\
\text { - Died of respiratory arrest }\end{array}$ \\
\hline $60 \mathrm{mM}$ & $2 \quad \begin{array}{l}\text { - Respiratory rate unstable under anesthesia } \\
\text { - Died of respiratory arrest }\end{array}$ \\
\hline $40 \mathrm{mM}$ & $2 \quad \begin{array}{l}\text { - Impaired balance } \\
\text { - Rigid legs } \\
\end{array}$ \\
& $\begin{array}{l}\text { - Seizure-like movement (fine tremor of the whole body) and tumbling (did cartwheels) } \\
\text { - Respiratory rate > 130 BPM under anesthesia }\end{array}$ \\
\hline $30 \mathrm{mM}$ & $\begin{array}{l}\text { - Normal behavior but somnolent, looked unwell, and showed generally depressed activity } \\
\text { - Respiratory rate of 80 BPM under anesthesia }\end{array}$ \\
\hline $20 \mathrm{mM}$ & $20 \quad \begin{array}{l}\text { - Normal behavior (vigorous exercise) } \\
\text { - Respiratory rate of 80 BPM under anesthesia }\end{array}$ \\
\hline
\end{tabular}

BPM: breaths per minute.

the RF receiver, and a 72-mm volume coil was used as the RF transmitter (Bruker). For analyzing the manganese distribution, a set of continuous two-dimensional (2D) multislice $T_{1}$-weighted $\left(T_{1} W\right)$ images was acquired using a spin-echo $(\mathrm{SE})$ pulse sequence. $\mathrm{T}_{1} \mathrm{~W}$ images were acquired with the following imaging parameters: repetition time (TR) $=400 \mathrm{~ms}$, echo time (TE) $=10.5 \mathrm{~ms}$, number of averages $(\mathrm{NA})=8$, number of slices $=24$, slice thickness (ST) $=0.5 \mathrm{~mm}$, flip angle $=90^{\circ} / 180^{\circ}$, field of view $(F O V)=$ width $40 \times$ length $30 \mathrm{~mm}^{2}$, and matrix size $=256 \times 256$; this lead to a voxel size of $0.156 \times 0.117$ $\times 0.5 \mathrm{~mm}^{3}$.

\section{Results}

Physiological monitoring following cannula implantation

A total of 35 SD rats were implanted with a cannula to allow stable injection of the contrast agent for MEMRI. Among them, 5 rats showed signs of impairment or were sacrificed in the process of cannula implantation. The latter was caused by deep implantation of the cannula through the medulla oblongata or loss of large amounts of CSF. The remaining 30 rats showed normal breathing, physical balance, and limb movements.

\section{Physiological monitoring following $\mathrm{MnCl}_{2} \mathrm{ICV}$ administration}

To monitor the physiological effects (Table 2), of the contrast agent, $\mathrm{MnCl}_{2}$ solutions of various doses were prepared before MEMRI. Under anesthesia, we administrated each concentration of the $\mathrm{MnCl}_{2}$ agent (as described in the Methods section) through the cannula.
With a dose of $80 \mathrm{mM}$ (2 rats) or $60 \mathrm{mM} \mathrm{MnCl} 2$ (2 rats), breathing was unstably maintained under anesthesia; the rats subjected to these doses did not recover from the anesthesia and later died. In animals that received a dose of $40 \mathrm{mM}$ (2 rats), we observed perplexing behaviors such as impaired balance, rigidity of limbs, fine tremor of the whole body, and tumbling, which continued until $3 \mathrm{~h}$ after recovery from anesthesia. Following an administration dose of $20 \mathrm{mM}$ (20 rats), rats showed normal breathing under anesthesia and normal motor behavior after recovery from anesthesia. Although rats also showed normal physiological parameters related to breathing and motor behaviors following a dose of 30 $\mathrm{Mm}$ (4 rats), some rats exhibited signs of depression and an unhealthy complexion after recovery from anesthesia. Therefore, the $20 \mathrm{mM}$ dose of $\mathrm{MnCl}_{2}$ was shown to be the optimal dose for MEMRI; this dose of $\mathrm{MnCl}_{2}$ does not damage the physiological activity and general condition of rats.

Image acquisition of the rat brain at different time points after injection

The MEMRI signal enhancement patterns of the rat brain changed according to the time points between 1 and $96 \mathrm{~h}$ following ICV administration of $20 \mathrm{mM} \mathrm{MnCl}_{2}$. Images were recorded preinjection and at 1, 7, 14, 19, 24, 31 and $96 \mathrm{~h}$ after injection. In $\mathrm{T}_{1}$-weighted images, detailed anatomical information could not be obtained at preinjection because there was insufficient contrast and signal. However, signal enhancement patterns were confirmed in the images of rats that had been administered the contrast agent. Therefore, we could obtain im- 


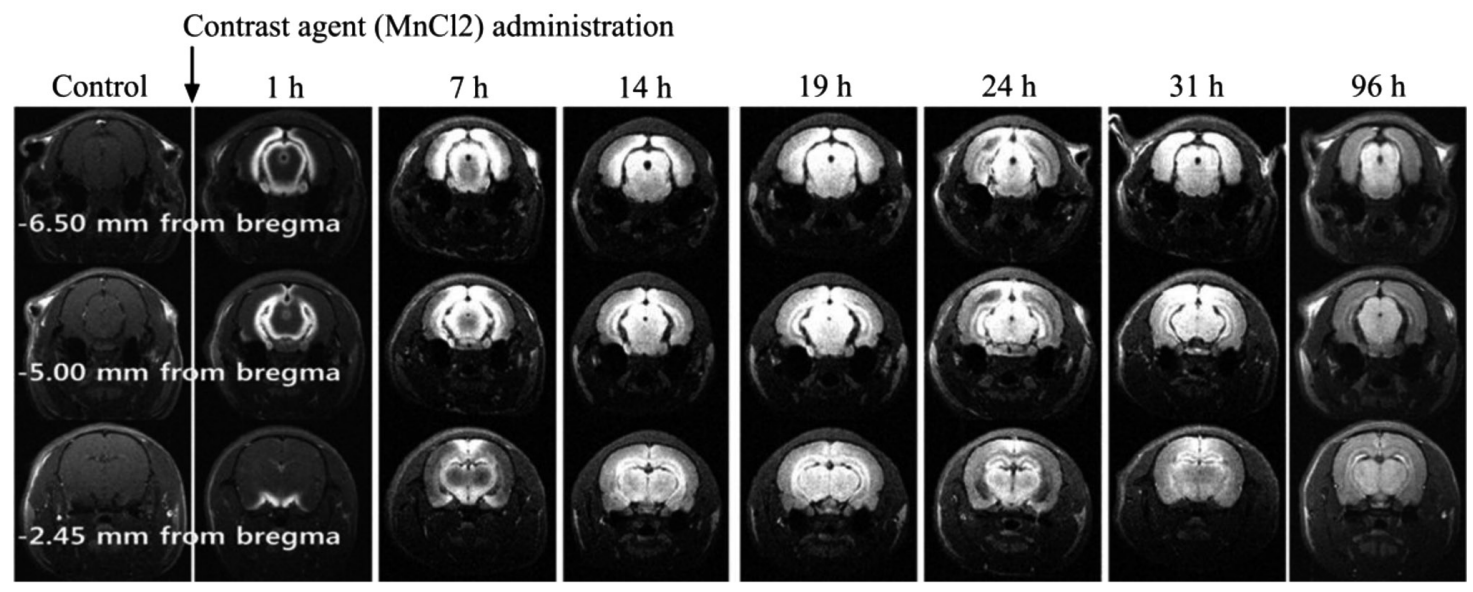

Fig. 3. Coronal views of the signal enhancement patterns of the rat brain according to the time delay after ICV administration of $20 \mathrm{mM} \mathrm{MnCl}_{2}$. The $\mathrm{T}_{1}$-weighted MEMRI results reflect the manganese distribution in a rat brain 1-96 $\mathrm{h}$ after $\mathrm{MnCl}_{2}$ administration.

ages of the anatomical structures of the rat brain depending on the time interval between administration of the contrast agent and image acquisition (Fig. 3).

At $1 \mathrm{~h}$ after administration of $\mathrm{MnCl}_{2}$, there was large signal enhancement in the regions of circumventricular organs (CVO), including the anterior lobe of the pituitary (Pit), cerebral peduncle (CP), dorsal part of the lateral geniculate complex, stratum oriens, dentate gyrus, and tuberal nucleus. After $7 \mathrm{~h}$, the signal enhancement was spread throughout the brain, although the signal distribution appeared heterogeneous. After $14 \mathrm{~h}$, signal enhancement was observed in the superior colliculus (SC), periaqueductal gray (PAG), and ventral part of the retrosplenial area. After $19 \mathrm{~h}$, the signal enhancement was present in all parts of the brain, but the signal was too bright. After $24 \mathrm{~h}$, optimal signal enhancement appeared in all parts of the brain: the enhancement was neither too weak nor too strong to observe the anatomical contrast. After $31 \mathrm{~h}$, there were no large changes in the distribution of enhanced signal. However, signal enhancement steadily declined within $96 \mathrm{~h}$.

\section{$T_{1}$-weighted spin-echo MEMRI}

To confirm that the contrast agent spreads sufficiently to all parts of the brain, we carried out $\mathrm{T}_{1}$-weighted spinecho MEMRI. Figure 4 shows two-dimensional $\mathrm{T}_{1}$ weighted data in the typical coronal, horizontal, and sagittal sections of the rat brain. The cornu ammonis (CA) formation, three main histological divisions of the hippocampus, and cortical areas were observed in the coronal section. The olfactory bulb, hippocampus, colliculus, and cerebellum were observed in the horizontal section. The olfactory bulb of the frontal area and cerebellum of the occipital area were observed in the sagittal section. In addition, the pons, medulla oblongata, and spinal cord region were observed behind the aforementioned regions.

\section{Discussion}

The present results suggest that $20 \mathrm{mM}$ of $\mathrm{MnCl}_{2}$ in a volume of $50 \mu \mathrm{l}$ is a physiologically stable dose for ICV administration in the rat and provides an optimal image for structural analysis of a rat brain $24 \mathrm{~h}$ after administration. For accurate ICV administration of $\mathrm{MnCl}_{2}$ for MEMRI, cannula implantation surgery was performed on 35 SD-rats. Among them, 5 rats showed signs of impairment or were sacrificed in the process of cannula implantation. The major potential causes of impairment or mortality from this procedure are presumed to be trauma to the brain stem, especially through puncture of the medulla oblongata and cerebellum due to deep injection of the cannula and the loss of large quantities of CSF. In fact, it is important to determine the route of contrast agent injection in MEMRI to select the appropriate dosage of contrast agent by each injection route. However, the limitations of the MEMRI experiment should also be considered: the structure of the targeted part cannot be analyzed accurately if the dose of $\mathrm{Mn}^{2+}$ is too low or high [21]. 
A.

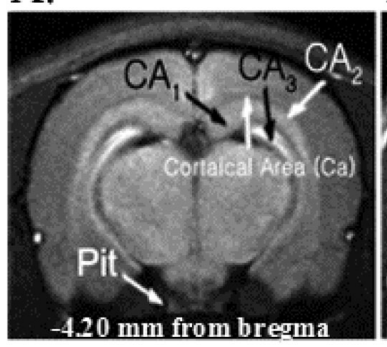

D.

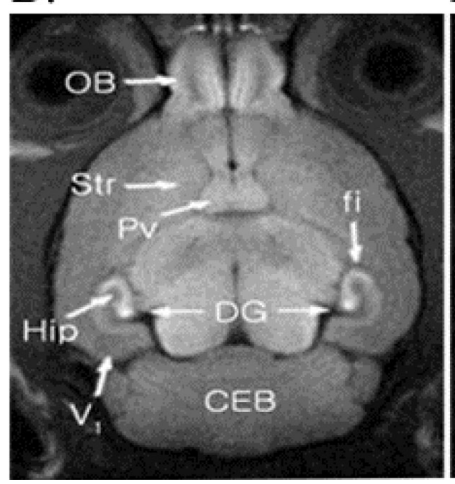

B.

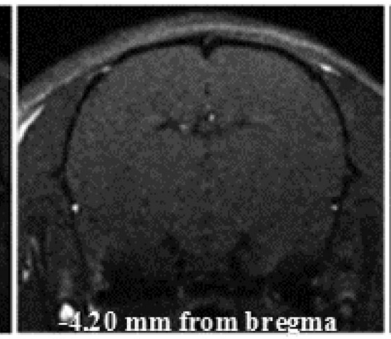

E.
C.
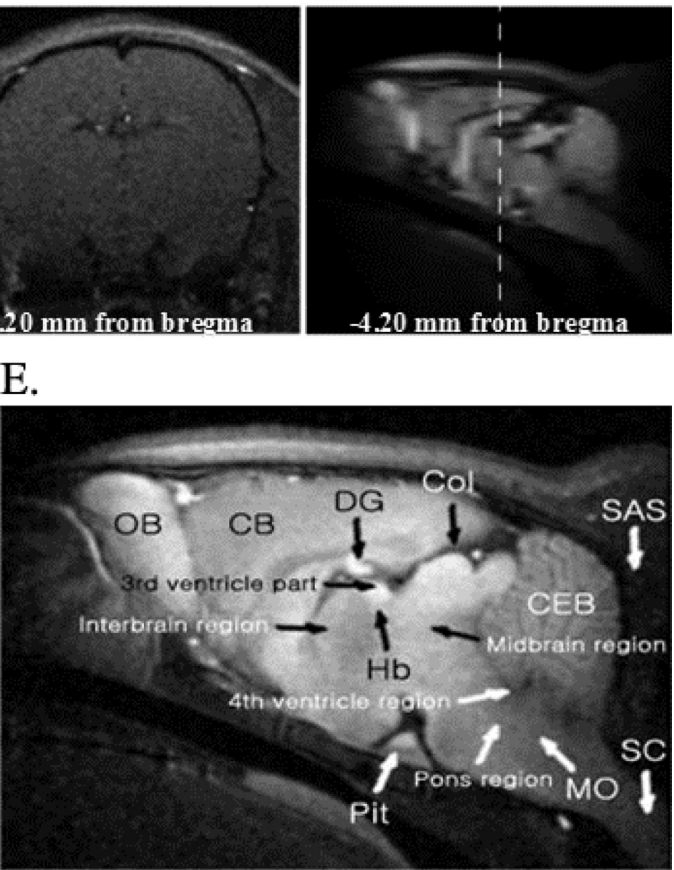

Fig. 4. $2 \mathrm{D} \mathrm{T}_{1}$-weighted spin-echo MEMRI images of a rat brain obtained $24 \mathrm{~h}$ after ICV administration of $20 \mathrm{mM} \mathrm{MnCl}_{2}$. The bright manganese-enhanced architecture is well visualized in (A), (D), and (E). (A) The coronal image showed cortical areas (Ca), the pituitary gland (Pit), and three main histological divisions of the hippocampus, the cornu ammonis formation of the hippocampus (CA1, CA2, CA3), as indicated by arrows. (B) The image shows no signal enhancement in a control animal that did not receive $\mathrm{MnCl}_{2}$. (C) The image displays the atlas level of the (A) and (B) images. (D) Typical horizontal view of the $\mathrm{T}_{1}$-weighted MEMRI data from a rat brain, which resolved the olfactory bulb (OB) layers. Also, the image shows excellent cytoarchitectonic contrast due to the presence of $\mathrm{Mn} 2+$ in regions such as striatum (Str), periventricular tissue zone (Pv), hippocampus (Hip), dentate gyrus (DG), fimbria of hippocampus (fi), Cerebellum (CEB), and primate visual cortex (V1). (E) Mid-sagittal view also showing excellent cytoarchitectonic contrast due to the presence of $\mathrm{MnCl}_{2}$ : Various regions of the olfactory bulb (OB), pituitary gland (Pit), colliculus (Col), dentate gyrus (DG), cerebellum (CEB), and spinal cord (SC) are clearly visible. The cerebrum (CB), interbrain, midbrain, pons, regions in the 4th and 3rd ventricles, subarachnoid space (SAS), habenula $(\mathrm{Hb})$, and medulla oblongata $(\mathrm{MO})$ are also visible.

In this study, the manganese was injected through the cannular into the cerebral ventricle, and the concentration of contrast agent was titrated while monitoring the rat's physiological status and behavior. Before MEMRI, $\mathrm{MnCl}_{2}$ was injected in a serial analysis of the $\mathrm{MnCl}_{2}$ concentration to determine the optimal dosage of manganese (Table 2). When over $60 \mathrm{mM}$ of $\mathrm{MnCl}_{2}$ was injected, the rats could not wake up from anesthesia, which indicates the toxicity of manganese. At a dose of $40 \mathrm{mM}$, neurologic abnormalities such as ataxia and tremor that accompanied disequilibrium were found. Such symptoms are similar to the disorders associated with over- exposure to manganese in humans. [27]. As such, the dosage of manganese used as a contrast agent will affect the motor and sensory nervous systems, and thus, it must be an important factor to consider when studying the anatomical structure and physiological function of the central nervous system using MEMRI. Therefore, further studies must be done on the injection route while simultaneously minimizing the risk of toxicity of the manganese by minimizing the dosage of contrast agent. In this study, $20 \mathrm{mM} \mathrm{MnCl}{ }_{2}$ was judged to be the optimal concentration; thus, intrathecal injection through the cannula was performed, and as a results, we observed whole- 
body fluttering behavior for up to tens of seconds after the rats woke up, particularly after injection of the contrast agent. This is likely due to the transient stress response that occurs when contrast agent is injected into the cerebral ventricle, and it could be an indicator signifying that the contrast agent was injected accurately. In addition, the time delay after contrast agent administration is an important factor to consider and optimize for anatomical imaging of rat brains using MEMRI; there are characteristic enhancement patterns corresponding to different acquisition time points following contrast agent injection (Fig. 2). This largely reflects differences in the infiltration time of the contrast agent. If the contrast agent exceeds a certain level, certain anatomical regions may exhibit poor image contrast.

As discussed above, contrast agents such as $\mathrm{MnCl}_{2}$ should be used at a concentration and dosage that limit the risk of toxicity. Additionally, MEMRI signal enhancements may differ more widely depending on the injected concentration of $\mathrm{MnCl}_{2}$, suggesting that certain concentrations may enable more accurate structural analysis. Therefore, more diverse dosages and acquisition times for $\mathrm{MnCl}_{2}$ could depend on the study objectives and provide more accurate images.

\section{Acknowledgment}

This study was supported by a Grant (2010K000816) from the Brain Research Center of the 21 st Century Frontier Research Program funded by the Ministry of Science and Technology of the Republic of Korea.

\section{References}

1. Aoki, I., Wu, Y.J., Silva, A.C., Lynch, R.M., and Koretsky, A.P. 2004. In vivo detection of neuroarchitecture in the rodent brain using manganese-enhanced MRI. Neuroimage 22: 1046-1059. [Medline] [CrossRef]

2. Barbeau, A. 1984. Manganese and extrapyramidal disorders (a critical review and tribute to Dr. George C. Cotzias). Neurotoxicology 5: 13-35. [Medline]

3. Bertin, A., Steibel, J., Michou-Gallani, A.I., Gallani, J.L., and Felder-Flesch, D. 2009. Development of a dendritic manganese-enhanced magnetic resonance imaging (MEMRI) contrast agent: synthesis, toxicity (in vitro) and relaxivity (in vitro, in vivo) studies. Bioconjug. Chem. 20: 760-767. [Medline] [CrossRef]

4. Crossgrove, J. and Zheng, W. 2004. Manganese toxicity upon overexposure. NMR Biomed. 17: 544-553. [Medline] [CrossRef]
5. Eschenko, O., Canals, S., Simanova, I., Beyerlein, M., Murayama, Y., and Logothetis, N.K. 2010. Mapping of functional brain activity in freely behaving rats during voluntary running using manganese-enhanced MRI: implication for longitudinal studies. Neuroimage 49: 2544-2555. [Medline] [CrossRef]

6. Eschenko, O., Canals, S., Simanova, I., and Logothetis, N.K. 2010. Behavioral, electrophysiological and histopathological consequences of systemic manganese administration in MEMRI. Magn. Reson. Imaging 28: 1165-1174. [Medline] [CrossRef]

7. Fa, Z., Zhang, P., Huang, F., Li, P., Zhang, R., Xu, R., Wen, Z., and Jiang, X. 2010. Activity-induced manganese-dependent functional MRI of the rat visual cortex following intranasal manganese chloride administration. Neurosci. Lett. 481: 110-114. [Medline] [CrossRef]

8. Gunter, T.E., Gavin, C.E., Aschner, M., and Gunter, K.K. 2006. Speciation of manganese in cells and mitochondria: a search for the proximal cause of manganese neurotoxicity. Neurotoxicology 27: 765-776. [Medline] [CrossRef]

9. Hoehn-Berlage, M. and Bockhorst, K. 1994. Quantitative magnetic resonance imaging of rat brain tumors: in vivo NMR relaxometry for the discrimination of normal and pathological tissues. Technol. Health Care 2: 247-254. [Medline]

10. Inui-Yamamoto, C., Yoshioka, Y., Inui, T., Sasaki, K.S., Ooi, Y., Ueda, K., Seiyama, A., and Ohzawa, I. 2010. The brain mapping of the retrieval of conditioned taste aversion memory using manganese-enhanced magnetic resonance imaging in rats. Neuroscience 167: 199-204. [Medline] [CrossRef]

11. Kollar, B., Martiniskova, Z., Klobucnikova, K., Vachalova, I., and Waczulikova, I. 2009. Solitary epileptic seizures in the clinical practice. Part II: findings of various modifications of EEG examination and imaging methods in patients who experienced solitary unprovoked epileptic seizure. $\mathrm{Neu}$ roendocrinol. Lett. 30: 487-490. [Medline]

12. Lee, J.H. and Koretsky, A.P. 2004. Manganese enhanced magnetic resonance imaging. Curr. Pharm. Biotechnol. 5: 529-537. [Medline] [CrossRef]

13. Lee, J.H., Silva, A.C., Merkle, H., and Koretsky, A.P. 2005. Manganese-enhanced magnetic resonance imaging of mouse brain after systemic administration of $\mathrm{MnCl} 2$ dose-dependent and temporal evolution of T1 contrast. Magn. Reson. Med. 53: 640-648. [Medline] [CrossRef]

14. Li, Y., Huang, T.T., Carlson, E.J., Melov, S., Ursell, P.C., Olson, J.L., Noble, L.J., Yoshimura, M.P., Berger, C., and Chan, P.H. 1995. Dilated cardiomyopathy and neonatal lethality in mutant mice lacking manganese superoxide dismutase. Nat. Genet. 11: 376-381. [Medline] [CrossRef]

15. Liu, C.H., D'Arceuil, H.E., and de Crespigny, A.J. 2004. Direct CSF injection of $\mathrm{MnCl}(2)$ for dynamic manganeseenhanced MRI. Magn. Reson. Med. 51: 978-987. [Medline] [CrossRef]

16. Lowe, A.S., Thompson, I.D., and Sibson, N.R. 2008. Quantitative manganese tract tracing: dose-dependent and activityindependent terminal labelling in the mouse visual system. NMR Biomed. 21: 859-867. [Medline] [CrossRef]

17. Lu, H., Xi, Z.X., Gitajn, L., Rea, W., Yang, Y., and Stein, 
E.A. 2007. Cocaine-induced brain activation detected by dynamic manganese-enhanced magnetic resonance imaging (MEMRI). Proc. Natl. Acad. Sci. U.S.A. 104: 2489-2494. [Medline] [CrossRef]

18. Natt, O., Watanabe, T., Boretius, S., Radulovic, J., Frahm, J., and Michaelis, T. 2002. High-resolution 3D MRI of mouse brain reveals small cerebral structures in vivo. J. Neurosci. Methods 120: 203-209. [Medline] [CrossRef]

19. Pautler, R.G. 2006. Biological applications of manganeseenhanced magnetic resonance imaging. Methods Mol. Med. 124: 365-386. [Medline]

20. Silva, A.C., Lee, J.H., Aoki, I., and Koretsky, A.P. 2004. Manganese-enhanced magnetic resonance imaging (MEMRI): methodological and practical considerations. NMR Biomed. 17: 532-543. [Medline] [CrossRef]

21. Silva, A.C., Lee, J.H., Wu, C.W., Tucciarone, J., Pelled, G., Aoki, I., and Koretsky, A.P. 2008. Detection of cortical laminar architecture using manganese-enhanced MRI. J. Neurosci. Methods 167: 246-257. [Medline] [CrossRef]

22. Stieltjes, B., Klussmann, S., Bock, M., Umathum, R., Mangalathu, J., Letellier, E., Rittgen, W., Edler, L., Krammer, P.H., and Kauczor, H.U. 2006. Manganese-enhanced magnetic resonance imaging for in vivo assessment of damage and functional improvement following spinal cord injury in mice. Magn. Reson. Med. 55: 1124-1131. [Medline] [CrossRef]

23. Watanabe, T., Frahm, J., and Michaelis, T. 2004. Functional mapping of neural pathways in rodent brain in vivo using manganese-enhanced three-dimensional magnetic resonance imaging. NMR Biomed. 17: 554-568. [Medline] [CrossRef]

24. Watanabe, T., Natt, O., Boretius, S., Frahm, J., and Michaelis, T. 2002. In vivo 3D MRI staining of mouse brain after subcutaneous application of MnCl2. Magn. Reson. Med. 48: 852-859. [Medline] [CrossRef]

25. Watanabe, T., Radulovic, J., Boretius, S., Frahm, J., and Michaelis, T. 2006. Mapping of the habenulo-interpeduncular pathway in living mice using manganese-enhanced 3D MRI. Magn. Reson. Imaging 24: 209-215. [Medline] [CrossRef]

26. Watanabe, T., Radulovic, J., Spiess, J., Natt, O., Boretius, S., Frahm, J., and Michaelis, T. 2004. In vivo 3D MRI staining of the mouse hippocampal system using intracerebral injection of MnCl2. Neuroimage 22: 860-867. [Medline] [CrossRef]

27. Zwingmann, C., Leibfritz, D., and Hazell, A.S. 2004. Brain energy metabolism in a sub-acute rat model of manganese neurotoxicity an ex vivo nuclear magnetic resonance study using [1-13C]glucose. Neurotoxicology 25: 573-587. [Medline] [CrossRef] 